\title{
COMPETITIVIDADE DO PALMITO DE PUPUNHA NO BRASIL EM DIFERENTES SISTEMAS DE PRODUÇÃO ${ }^{1}$
}

\author{
Naisy Silva Soares ${ }^{2}$, Eliane Pinheiro de Sousa ${ }^{3}$, Sidney Araujo Cordeiro e Márcio Lopes da Silva ${ }^{5}$
}

\begin{abstract}
RESUMO - Neste artigo, buscou analisar a competitividade da produção de palmito de pupunha no Brasil, fazendo estudo comparativo entre o sistema produtivo praticado em áreas motomecanizáveis com irrigação e em áreas não motomecanizáveis sem irrigação. Para atingir esse objetivo, empregou-se a matriz de análise política (MAP). Os resultados indicaram que esses dois sistemas de produção considerados tiveram rentabilidade positiva nos mercados interno e externo, evidenciando que a produção de palmito de pupunha é competitiva, porém os lucros foram reduzidos em razão das políticas públicas adotadas.
\end{abstract}

Palavras-chave: Palmito de pupunha, Competitividade e Matriz de Análise Política.

\section{COMPETITIVELY OF PALM HEART OF PEJIBAYE IN BRAZIL IN DIFFERENT PRODUCTION SYSTEMS}

\begin{abstract}
This article analyzes the competitiveness of pejibaye heart of palm production in Brazil, doing one comparative study among the productive system practiced in flat areas with irrigation and in hilly areas without irrigation. For this, the policy analysis matrix (PAM) was utilized. The results showed evidence that the two production systems considered had positive profitability in domestic and international markets, demonstrating that the production of pejibaye palm of heart is competitive; however, the profits were reduced by the public policies adopted.
\end{abstract}

Palavras-chave: Pejibaye heart of palm, Competitiveness and Policy Analysis Matrix..

\section{INTRODUÇÃO}

A pupunha é uma palmeira originária da Região Amazônica, sendo domesticada e disseminada nessa região e na América Central por povos indígenas. É uma ótima alternativa para a produção de palmito, podendo ser explorada em plantios organizados, e possui características desejáveis como precocidade, perfilhamento, rendimento e qualidade de seu palmito (CHAIMSOHN, 2000; PADILHA et al., 2003).

O cultivo da pupunha para produção de palmito vem despertando, desde a década de 1970, o interesse de agricultores de todo o país, devido à alta demanda, tanto interna quanto externa, por palmito de boa qualidade e à alta lucratividade da atividade. A busca por novas opções de cultivo faz também que empresários de outros setores se aventurem no negócio do palmito de pupunha (BOVI, 2000; BENTES-GAMA et al., 2002).

O Brasil é o maior produtor e consumidor de palmito do mundo. Porém, já não possui mais o título de maior exportador, o que ocorria na época em que exportava menos de $10 \%$ de sua produção. A perda desse mercado deveu-se ao fato de o palmito brasileiro apresentar baixa qualidade, resultante do processo de extrativismo, e de ser um produto não ecológico, pois é sustentado pelo corte de palmeiras nativas (SAMPAIO, 2007).

Devido ao potencial comercial do palmito de pupunha, muitos países latinoamericanos estão investindo no seu cultivo e industrialização. O interesse

\footnotetext{
${ }^{1}$ Recebido em 03.07.2009 e aceito para publicação em 31.10.2011.

${ }^{2}$ Professora Assistente da Universidade Estadual de Santa Cruz, UESC, Brasil. E-mail: < naisysilva@yahoo.com.br>.

${ }^{3}$ Universidade Regional do Cariri, URCA, Brasil. E-mail: <pinheiroeliane@hotmail.com>.

${ }^{4}$ Universidade Federal do Piauí, UFPI, Brasil. E-mail: <sidneycordeiro@ufpi.edu.br>.

${ }^{5}$ Departamento de Engenharia Florestal da Universidade Federal de Viçosa, UFV, Brasil. E-mail: <marlosil@ufv.br>.
} 
para cultivar a pupunha tem aumentado fortemente nos últimos anos (VILLACHICA, 1996), especialmente para a produção de palmito. Dois fatores estão facilitando esse aumento: a existência de mercado em nível mundial e a disponibilidade de tecnologia para o cultivo e industrialização da pupunha para palmito (VERRUMABERNARDI, 2007).

O esgotamento da oferta de matéria-prima proveniente da coleta extrativa no Centro Sul, a intensificação da fiscalização de órgãos oficiais impedindo a devastação predatória, o baixo custo da taxa de reflorestamento e o alto preço do produto no mercado nacional e internacional são fatores que vêm estimulando o investimento e produção racional do palmito industrializado (VERRUMA-BERNARDI, 2007).

Nesse contexto, estudos que mostrem os efeitos das políticas públicas na produção de palmito tornam-se relevantes, pois permitem identificar pontos de estrangulamento na sua estrutura de custos, objetivando a manutenção e, ou, a ampliação da capacidade produtiva e de exportação do palmito do Brasil. Estudos desse tipo podem, também, explicar os impactos de políticas públicas na atividade, o que subsidiaria a adoção de medidas, contribuindo para a tomada de decisão de alocação dos recursos e do planejamento de estratégias comerciais.

Diante disso, este trabalho objetivou analisar a competitividade da produção de palmito de pupunha no Brasil, comparando sistemas de produção. Especificamente, pretenderam-se determinar a lucratividade privada e social na produção do palmito de pupunha para diferentes sistemas tecnológicos; identificar os efeitos de políticas públicas sobre os diferentes sistemas adotados, em relação ao mercado externo; e mensurar os indicadores que avaliam o grau de competitividade do setor produtivo, assim como a eficiência econômica e os efeitos das políticas nesse setor, levando em consideração os resultados privados e sociais.

\section{MATERIAL E MÉTODOS}

\subsection{Referencial teórico}

Este trabalho teve como referência a abordagem que relaciona a competitividade aos custos.

Segundo Rosado (1997), o conhecimento dos componentes dos custos é útil para a compreensão da competitividade. Para essa autora, a competitividade resulta da interação entre os custos de produção e todos os custos adicionais incorridos com o deslocamento de mercadoria para o mercado internacional. Nesse sentido, para determinar a competitividade é necessário considerar variáveis como eficiência produtiva, política de preços dos insumos, taxa de juros, taxa de câmbio e política de impostos e subsídios.

O conceito de eficiência associa a competitividade de uma economia às condições gerais do processo de produção. Assim, o progresso tecnológico é elemento central na configuração e evolução dos sistemas econômicos e dos fluxos internacionais de comércio, bem como o melhor aproveitamento de economias de escala, maior capacitação de mão de obra etc. (HAGUENAUER, 1989; ALVES, 2002). Os indicadores de eficiência relacionam-se com a comparação dos preços e custos unitários de um país e com determinado conjunto de competidores internacionais (IE/UNICAMP et al., 1993). Além disso, também é relevante mencionar que os produtos comercializados internacionalmente estão sujeitos a impostos, tarifas ou subsídios que possam provocar distorções consideráveis sobre a competitividade (FERREIRA NETO, 2005).

Assim, a competitividade é influenciada por diversos fatores inter-relacionados, como tecnologia disponível e a forma como é aplicada, preços domésticos dos insumos produtivos, taxa de câmbio, taxa de paridade entre os parceiros comerciais do país, custos de transporte, estrutura de incentivos, barreiras tarifárias e não tarifárias no país importador, qualidade e imagem do produto etc. (BNDES, 1991 citado por FERREIRA NETO, 2005).

\subsection{Referencial analítico}

\subsubsection{Considerações preliminares}

O instrumental utilizado para atingir os objetivos deste trabalho foi o da Matriz de Análise Política (MAP), de Monke e Pearson (1989).

Com a MAP, podem-se identificar incentivos ou desincentivos para agentes econômicos; analisar o impacto de políticas diretas em nível de cadeia; verificar os efeitos de políticas sobre a lucratividade privada; e examinar os impactos favoráveis ou desfavoráveis à sociedade relativos a atividades econômicas (ALVES, 2002). Por isso, esse método é frequentemente utilizado na análise da cadeia produtiva de produtos da agropecuária no Brasil e no exterior (NELSON, 1991; NELSON; PANGGABEAN, 1991; ROSADO, 1997; 
AHMAD; MARTINI, 2000; MARRA, 2001; MARTINS, 2001; ALVES, 2002; MOHANTY et al., 2002; FERREIRA NETO, 2005; MOSS, 2006; ROSADO et al., 2006).

No Brasil, e especificamente na área florestal, apenas no estudo de Rosado et al. (2006) a MAP foi utilizada para analisar a competitividade e os efeitos das políticas públicas sobre a produção da borracha natural nos Estado de São Paulo e Mato Grosso. Esses autores constataram que a produção da borracha natural naqueles Estados está sendo prejudicada pelas políticas públicas, mas, apesar disso, é lucrativa e competitiva.

No exterior, podem-se citar os estudos de Maryani e Irawanti (1997), Hadi e Budhi (1997) e Endom (1999), utilizando a MAP na área florestal. Maryani e Irawanti (1997) analisaram os impactos das políticas públicas na competitividade da produção de óleo de palma e da madeira industrial processada em Sumatra, Indonésia, mais precisamente na província de Riau, em 1997, que é composta pelos distritos de Pakan baru, Kampar, Bengkalis, Inderagiri Hulu, Kepulauan Riau e Batam. Os referidos autores concluíram que ambas as mercadorias são economicamente eficientes devido às políticas governamentais.

Hadi e Budhi (1997) estudaram a eficiência econômica e a vantagem comparativa dos pequenos produtores de borracha natural de Sumatra, Indonésia, em 1997, considerando o sistema agroflorestal e a monocultura. Esses autores constataram que os dois sistemas de produção não eram competitivos e que, no sistema agroflorestal, as perdas são maiores que no sistema de monocultura para os pequenos produtores.

Já Endom (1999) verificou os impactos das políticas públicas na competitividade da indústria de madeira na província de Jambi, distrito de Bungo Tebo em Kabupaten, Indonésia, em 1997. As regiões que compuseram a amostra foram: PT Rimba Karya Indah,
PT Dalek Esa Hutani, PT Gaya Wahana Timber e PT Sylvagama. Os resultados revelaram que essa indústria é relativamente competitiva e possui elevada eficiência. Porém, as políticas públicas contribuíram para que o preço da tora no mercado interno ficasse menor que o preço mundial.

Ressalta-se que a MAP apresenta como limitação o fato de os resultados serem para um ano-base estáticos e aplicáveis a esse ano. Porém, podem ser feitas projeções de mudanças futuras nos seus parâmetros (como preços internacionais de produtos e insumos, salários, taxa de câmbio, tecnologia etc.) para simular cenários de vantagem competitiva, à medida que os lucros alteram, em resposta a parâmetros que estão variando (ROSADO, 1997).

\subsubsection{Operacionalização do modelo}

A MAP expressa a lucratividade, definida como a diferença entre receitas e custos, e mensura o efeito das divergências (políticas “distorcivas” e falhas de mercado), resultado da diferença entre valores privados e valores sociais. A MAP é composta por duas colunas de custos, uma para insumos comercializáveis (tradeable) e outra para fatores domésticos (nontradeable). Os insumos intermediários - fertilizantes, pesticidas, sementes, eletricidade, transporte e combustível - são divididos em seus componentes de insumos comercializáveis e não comercializáveis (Tabela 1) (ALVES, 2002).

A manipulação dos valores contidos na MAP dá origem aos indicadores a seguir:

a) Lucro privado (D): expressa o lucro obtido a preços de mercado, ou a preços privados (equação 1). Como valores praticados no mercado, esses sofrem interferências dos governos, na forma de tributos ou subsídios. $D=A-B-C$ (1), em que; $A=p^{d} q^{d} ; C=\sum_{=1}^{n} w_{j}^{d} l_{j}^{d}$; $\mathrm{C}=\sum_{j=1}^{\mathrm{n}} \mathrm{w}_{\mathrm{j}}^{\mathrm{d}} \mathrm{l}_{\mathrm{j}}^{\mathrm{d}} ; \mathrm{A}=$ receita privada; $\mathrm{B}=$ custo dos insil

Tabela 1 - Matriz de Análise Política (MAP).

Table 1 - Policy Analysis Matrix (PAM).

\begin{tabular}{lccc}
\hline Itens & Receitas & & Custos \\
\cline { 3 - 4 } & & Insumos Comercializáveis & Fatores Domésticos \\
\hline Preços Privados & $\mathrm{A}$ & $\mathrm{B}$ & $\mathrm{C}$ \\
Preços Sociais & $\mathrm{E}$ & $\mathrm{F}$ & $\mathrm{G}$ \\
Efeitos de divergências & $\mathrm{I}$ & $\mathrm{J}$ & $\mathrm{K}$ \\
e eficiência política & & & $\mathrm{H}$ \\
\hline
\end{tabular}

Fonte: MONKE; PEARSON, (1989).

Source: MONKE; PEARSON, (1989).

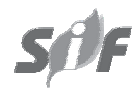

Revista Árvore, Viçosa-MG, v.35, n.6, p.1287-1297, 2011 
comercializáveis externamente; $\mathrm{C}$ = custo dos insumos domésticos; $\mathrm{p}^{\mathrm{d}}=$ preço privado do produto; $\mathrm{q}^{\mathrm{d}}=$ quantidade total privada de determinado produto; $\mathrm{p}_{\mathrm{i}}^{\mathrm{d}}=$ preço privado do insumo $\mathrm{i} ; \mathrm{q}_{\mathrm{i}}^{\mathrm{d}}=$ quantidade privada do insumo i utilizado na produção de dado bem; $\mathrm{W}_{\mathrm{j}}^{\mathrm{d}}=$ preço privado do insumo $\mathrm{j}$; e $1_{\mathrm{j}}^{\mathrm{d}}$; = quantidade privada do insumo $\mathrm{j}$.

O cálculo da lucratividade privada mostra a competitividade da cadeia produtiva. Se os lucros privados forem negativos $(D<0)$, os operadores estarão ganhando uma taxa de retorno subnormal e, se os lucros privados forem positivos ( $\mathrm{D}>0$ ), os operadores estarão ganhando uma taxa de retorno sobrenormal, indicando que pode ocorrer expansão do sistema de produção. O lucro normal acontece se D = 0 (ROSADO et al., 2006).

b) Lucro social (H): representa o lucro alcançado a preços sociais (equação 2), expresso por: $H=E-F-G(2))$, em que $\mathrm{E}=\mathrm{p}^{\mathrm{s}} \mathrm{q}^{\mathrm{s}} ; \mathrm{F}=\sum^{\mathrm{n}} \mathrm{p}_{\mathrm{i}}^{\mathrm{s}} \mathrm{q}_{\mathrm{i}}^{\mathrm{s}}$; $\mathrm{G}=\sum^{\mathrm{n}} \mathrm{w}_{\mathrm{j}}^{\mathrm{s}} \mathrm{l}_{\mathrm{j}}^{\mathrm{s}} ; \mathrm{E}=$ receita social; $\mathrm{F}=$ custo dos insumos comèrcializáveis; $\mathrm{G}$ = custo dos insumos domésticos; $\mathrm{p}^{\mathrm{s}}=$ preço social do produto; $\mathrm{q}^{\mathrm{s}}=$ quantidade total do produto; $\mathrm{P}_{\mathrm{i}}^{\mathrm{s}}$ = preço social do insumo $\mathrm{i}$; $\mathrm{q}_{\mathrm{i}}^{\mathrm{s}}=$ quantidade do insumo i utilizado; $\mathrm{W}_{\mathrm{i}}^{\mathrm{s}}=$ preço social do insumo $\mathrm{j}$; e $1_{\mathrm{j}}^{\mathrm{s}}=$ quantidade do insumo j utilizado.

Esses valores não sofrem interferências de governos. Assim, são considerados valores sociais ou econômicos e medem a eficiência do sistema de produção. Como medida de eficiência ou vantagem comparativa, o lucro social, quando negativo, indica que o sistema não é considerado economicamente viável no contexto de mercado internacional, sem assistência do governo. Tem-se uma indicação de que tal sistema não assegura a alocação economicamente eficiente de recursos escassos, dado que produz a custos sociais superiores aos custos de importação (ALVES, 2002; VIEIRA et al., 2001).

c) Efeitos das divergências e da eficiência política: aqui são analisadas as diferenças entre as avaliações privadas e sociais de receitas, custos e lucros, que devem ser explicadas pelos efeitos da distorção política ou pelas imperfeições nos mercados de produtos e fatores.

A mensuração dos efeitos das divergências e da eficiência política pode ser representada conforme as equações $3,4,5$ e 6 : Transferência de receitas: $I=A-E$ (3), Transferência de insumos: $J=B-F$ (4), Transferência de fatores: $K=C-G$ (5) e Transferência líquida: $L=D-H$ ou $L=I-J-K(6)$.
As transferências de receitas estão associadas à produção e as transferências de insumos, aos custos de insumos comercializáveis, que resultam de políticas que causam divergências entre os preços domésticos dos produtos e os preços internacionais, como políticas específicas de produtos (taxas ou subsídios) e política cambial. Por fim, as falhas de mercado, devido a informações imperfeitas ou ao desenvolvimento ineficiente das instituições, que consistem em características do funcionamento de mercados, podem também influenciar os preços dos produtos e fatores. As transferências líquidas combinam efeitos de políticas “distorcivas” com aqueles de falhas de mercado de fator e políticas eficientes para compensá-los (ALVES, 2002).

A comparação entre sistemas de produção que geram bens idênticos foi realizada com base nos indicadores a seguir (ROSADO et al., 2006; MOSS, 2006; FERREIRA NETO, 2005):

a) Razão do Custo Privado (RCP): a RCP mostra quanto o sistema pode pagar pelos fatores domésticos, permanecendo competitivo, ou seja, equilibrando a receita com a despesa (sem lucro nem perda), após alcançar lucros normais. Para que o produtor atinja esse objetivo, é necessário que os custos de seus fatores domésticos sejam menores que seus valores adicionais (diferença entre receita e custos dos insumos comercializáveis), a preços privados. Desse modo, para a maximização dos lucros é indispensável a minimização dessa razão, por meio do controle dos custos dos fatores domésticos.

Essa razão é calculada como apresentado na equação 7 .

$$
\mathrm{RCP}=\mathrm{C} /(\mathrm{A}-\mathrm{B})
$$

A RCP pode indicar se os fatores domésticos estão recebendo o seu retorno normal $(\mathrm{RCP}=1)$, acima do retorno normal $(\mathrm{RCP}<1)$ ou abaixo do retorno normal ( RCP > 1).

b) Custo dos Recursos Domésticos (CRD): consiste em uma medida de vantagem comparativa mais criteriosa que a lucratividade social. Indica o comportamento da lucratividade social, ou seja, quanto se despende de recursos domésticos, em valores sociais, para gerar uma unidade de divisas por meio da exportação (equação 8).

$$
\mathrm{CRD}=\mathrm{G} /(\mathrm{E}-\mathrm{F})
$$

Revista Árvore, Viçosa-MG, v.35, n.6, p.1287-1297, 2011 
Minimizar o CRD é o equivalente a maximizar os lucros sociais. O CRD $<1$ significa que se estaria utilizando menos de um dólar de recursos domésticos para gerar um dólar de divisas e vice-versa. Indica, também, eficiência da produção.

c) Coeficiente de Proteção Nominal (CPN): indica o impacto da política que provoca divergências entre preços privados e sociais. É a razão entre os preços privados e sociais (equação 9), sendo expressa por:

$$
\mathrm{CPN}=\mathrm{A} / \mathrm{E}
$$

Tem-se o CPN sobre produtos comercializáveis (CPNp) e sobre os insumos comercializáveis (CNPi) (equações 10 e 11, respectivamente), que podem ser representadas por:

$$
\begin{aligned}
& \mathrm{CPNp}=\mathrm{A} / \mathrm{E} \\
& \mathrm{CPNi}=\mathrm{B} / \mathrm{F}
\end{aligned}
$$

Um CPNp > 1 mostra que existe transferência de renda da sociedade para os produtores e vice-versa e que um CPNi > 1 indica transferência de renda negativa aos produtores, pois os custos dos insumos comercializáveis são aumentados pela política e vice-versa.

d) Coeficiente de Proteção Efetiva (CPE): este coeficiente é importante, pois permite indicar a extensão dos incentivos ou do desestímulo que os sistemas produtivos recebem das políticas de preços de produtos e de insumos comercializáveis. Se CPE $>1$, os lucros privados são maiores que seriam sem as políticas dos produtos e insumos comercializáveis conjuntamente, ou seja, o efeito líquido das políticas contribui para aumento do lucro privado e vice-versa. O CPE é obtido por meio da razão das diferenças entre receitas e custos comercializáveis (equação 12), dada por:

$$
\mathrm{CPE}=(\mathrm{A}-\mathrm{B}) /(\mathrm{E}-\mathrm{F})
$$

e) Coeficiente de Lucratividade (CL): este coeficiente mede o efeito dos incentivos de todas as políticas. É obtido pela razão entre lucros privados e sociais (equação 13), expressa por:

$$
C L=(A-B-C) /(E-F-G)=D / H
$$

f) Taxa de Subsídios aos Produtores (TSP): esta taxa mostra a proporção de renda, em valores sociais, que seria requerida para manter a eficiência econômica se um subsídio ou imposto fosse substituído por um conjunto de políticas de outra natureza. É uma medida da transferência líquida de políticas (L), como uma proporção das receitas sociais totais (E) (equação 14). Quanto menor a TSP, menos distorcido será o sistema.

$$
\mathrm{TSP}=\mathrm{iL} / \mathrm{Ei}=\mathrm{i}(\mathrm{Di}-\mathrm{iH}) / \mathrm{E}
$$

\subsubsection{Sistemas de produção do palmito}

Foram analisados dois sistemas de produção do palmito.

O sistema I representa um nível de produtividade igual a 2.000 hastes ou $800 \mathrm{~kg}$ por hectare, no segundo ano. Nesse sistema, o plantio é feito em áreas motomecanizáveis com irrigação, espaçamento de $2 \mathrm{~m}$ x $1 \mathrm{~m}$, com 5.000 plantas por hectare. Os custos desse sistema de produção são com: aração, gradagem, marcação de covas, coveamento, calagem, adubação, plantio e replantio, capina manual, roçada manual, manejo de irrigação, adubação de cobertura, colheita manual, mudas, fertilizantes, defensivos, energia elétrica e conjunto de irrigação por aspersão (CEDAGRO, 2007).

O sistema II é similar ao sistema I com relação à produtividade, espaçamento e plantas por hectare. Porém, o plantio é feito em áreas não motomecanizáveis não irrigadas. Os custos desse sistema de produção incluem limpeza da área, marcação de covas, coveamento, calagem, adubação, plantio e replantio, capina manual, roçada manual, colheita manual, mudas, fertilizantes e defensivos (CEDAGRO, 2007).

\subsubsection{Fonte de dados}

Os preços privados do palmito foram obtidos no Instituto de Economia Agrícola (IEA, 2009) e são os praticados no Estado de São Paulo. Já o preço social é do estudo de Chaimsohn (2006) e refere-se ao preço na Costa Rica, país grande produtor e exportador de palmito, conforme relatou Merecí (2008).

Os preços privados dos insumos comercializáveis e dos fatores de produção foram extraídos do Centro de Desenvolvimento do Agronegócio (CEDAGRO, 2008) e referem-se aos preços no Estado do Espírito Santo.

Com relação aos preços sociais dos insumos comercializáveis e dos fatores de produção, estes foram obtidos em Chaimsohn (2006) e referem-se aos preços na Costa Rica. Esses preços também foram 
obtidos no site do Ministerio de Agricultura, Ganadería, Acuacultura Y Pesca del Ecuador, mais precisamente no Servicio de Información y Censo Agropecuario (SICA, 2009) e são os preços praticados no Equador.

Ressalta-se que os preços sociais dos insumos e o valor social do produto são os próprios preços internacionais (MOSS, 2006).

Para o cálculo dos custos, adotou-se um horizonte temporal de dois anos.

Os preços dos insumos e do palmito no exterior foram internalizados no Brasil, multiplicando-os pela taxa de câmbio do período a que se referiam. Posteriormente, os preços internos foram corrigidos pelo Índice Geral de Preços - Disponibilidade Interna (IGP-DI) da Fundação Getúlio Vargas (IPEADATA, 2009). Com isso, os preços utilizados para o cálculo dos indicadores estão em R\$ de fevereiro de 2009.

\section{RESULTADOS}

Os resultados das lucratividades privadas e sociais, das transferências financeiras associadas aos preços do produto e dos insumos comercializáveis, assim como as transferências líquidas para os dois sistemas de produção do palmito de pupunha considerados, são apresentados na Tabela 2 .

Para obter melhor análise comparativa entre os sistemas de produção considerados, principalmente com relação à alocação de recursos, os indicadores privados e sociais foram obtidos a partir dos dados da MAP. Na Tabela 3 são apresentados esses resultados.

\section{DISCUSSÃO}

Com base nos resultados estimados (Tabela 2), verificou-se que os dois sistemas de produção apresentam lucros positivos, tanto do ponto de vista privado quanto social, demonstrando que a produção de palmito de pupunha é competitiva em ambos os sistemas, apesar das condições vigentes de políticas públicas.

No tocante à lucratividade privada, constatou-se que a magnitude do valor do lucro do palmito de pupunha nos dois sistemas produtivos foi praticamente idêntica, contrastando com o estudo desenvolvido por Hernandez (2008), em Ilha Solteira, SP, no qual se ressalta que a pupunheira apresenta menor rentabilidade; quando não se adota o sistema de irrigação, isso pode ser atribuído à mortalidade e à postergação do início de produção da pupunheira em sistema sem irrigação.

Já com relação ao contexto social, constatou-se que o sistema de produção praticado em áreas motomecanizáveis com irrigação apresentou lucro líquido inferior ao obtido em áreas não motomecanizáveis sem irrigação, indicando que o sistema (I) foi menos eficiente do que o sistema (II). Assim, o alto investimento empregado no sistema produtivo com irrigação não tem compensado o acréscimo de produtividade gerado pelo fornecimento de água às plantas.

Os dados também evidenciam que a rentabilidade privada do palmito de pupunha no Brasil foi muito menor que sua contrapartida social. Essa realidade também é observada em outras culturas, como a cana-de-açúcar (FERREIRA NETO, 2005) e o café (MOSS, 2006). Para esses autores, tal resultado pode ser proveniente dos

Tabela 2 - Matriz de Análise Política (MAP) - Produção de palmito de pupunha no Brasil, janeiro de 2009. Table 2 - Policy Analysis Matrix (PAM) - Production pejibaye of heart of palm in Brazil, January of 2009.

\begin{tabular}{|c|c|c|c|c|}
\hline \multirow[t]{2}{*}{ Especificação do sistema de produção } & \multirow[t]{2}{*}{ Receitas } & \multicolumn{2}{|c|}{ Custos } & \multirow[t]{2}{*}{ Lucro Líquido } \\
\hline & & $\begin{array}{c}\text { Insumos } \\
\text { Comercializáveis }\end{array}$ & $\begin{array}{c}\text { Fatores } \\
\text { Domésticos }\end{array}$ & \\
\hline \multicolumn{5}{|l|}{ (I) Áreas motomecanizáveis com irrigação } \\
\hline $\begin{array}{l}\text { Preços Privados } \\
\text { Valorações Sociais } \\
\text { Efeitos de Divergências }\end{array}$ & $\begin{array}{c}7,80 \\
10,20 \\
-2,40 \\
\end{array}$ & $\begin{array}{l}5,49 \\
4,91 \\
0,58\end{array}$ & $\begin{array}{l}1,96 \\
1,73 \\
0,22\end{array}$ & $\begin{array}{r}0,35 \\
3,55 \\
-3,20 \\
\end{array}$ \\
\hline \multicolumn{5}{|c|}{ (II) Áreas não motomecanizáveis sem irrigação } \\
\hline $\begin{array}{l}\text { Preços Privados } \\
\text { Valorações Sociais } \\
\text { Efeitos de Divergências }\end{array}$ & $\begin{array}{l}7,80 \\
10,20 \\
-2,40\end{array}$ & $\begin{array}{l}5,76 \\
4,41 \\
1,34\end{array}$ & $\begin{array}{l}1,70 \\
1,62 \\
0,08\end{array}$ & $\begin{array}{r}0,34 \\
4,16 \\
-3,82 \\
\end{array}$ \\
\hline
\end{tabular}

Fonte: Dados da pesquisa.

Revista Árvore, Viçosa-MG, v.35, n.6, p.1287-1297, 2011 
Tabela 3 - Indicadores de competitividade privados e sociais gerados pela MAP. Table 3 - Private and social indicators of competitiveness generated by MAP.

\begin{tabular}{lc}
\hline \multicolumn{1}{c}{ Indicadores } & Sistema (I) \\
\hline Razão do Custo Privado (RCP) & 0,85 \\
Custo dos Recursos Domésticos (CRD) & 0,33 \\
Coeficiente de Proteção Nominal sobre produtos comercializáveis (CPNp) & 0,83 \\
Coeficiente de Proteção Nominal sobre insumos comercializáveis (CPNi) & 0,28 \\
Coeficiente de Proteção Efetiva (CPE) & 1,12 \\
Coeficiente de Lucratividade (CL) & 0,44 \\
Taxa de Subsídio aos Produtores (TSP) & 0,10 \\
\hline
\end{tabular}

Fonte: Dados da pesquisa.

efeitos de políticas públicas adotadas, que podem estar relacionadas à ineficiência pública na tributação, na taxa de câmbio, nos encargos sociais e nas políticas sociais, assim como falhas de mercado.

Observou-se ainda que os preços privados do palmito de pupunha são inferiores aos seus preços sociais, o que indica transferência negativa de $\mathrm{R} \$ 2,40$ por kg de produto. Em outros termos, a diferença entre esses preços resulta em transferência negativa de 30,8\%. Essa divergência é decorrente de políticas públicas ineficientes e, ou, falhas de mercado.

Verificou-se, dessa forma, que a intervenção governamental implementada nesses sistemas produtivos foi danosa para os produtores de palmito de pupunha no Brasil. Essa situação também foi observada em outros países, como a China, em que o trabalho realizado por Fang e Beghin (2000) para 16 commodities nos anos de 1996, 1997 e 1998, com emprego da MAP, apontou que em apenas $20 \%$ dos casos os preços internos excederam os internacionais.

No tocante às transferências dos custos dos insumos comercializáveis, verificou-se, a partir da Tabela 2, que tais transferências foram de $\mathrm{R} \$ 0,58$ por $\mathrm{kg}$ no sistema (I) e de $\mathrm{R} \$ 1,34$ por kg no sistema (II). A taxação sobre o preço dos insumos comercializáveis foi maior em áreas não motomecanizáveis sem irrigação do que em áreas motomecanizáveis com irrigação, constituindo uma forma de incentivo do governo aos produtores de palmito de pupunha para adoção do sistema (I) em detrimento do sistema (II). Portanto, nota-se a presença de políticas intervencionistas nesse mercado, o que gera divergências entre os custos dos insumos comercializáveis privados e internacionais, de modo que, se as alíquotas incidentes sobre os preços desses insumos fossem minimizadas, a produção de palmito de pupunha no Brasil poderia se tornar mais rentável, refletindo sua competitividade.
Quando, entretanto, se trata das transferências referentes aos fatores domésticos, os valores foram de $\mathrm{R} \$ 0,22$ por kg no sistema (I) e R \$0,08 por kg no sistema (II), indicando que o sistema produtivo aplicado a áreas motomecanizáveis com irrigação registrou o maior custo de fatores domésticos, visto que esse sistema produtivo requer maior uso de mão de obra para sua operação, comparativamente ao sistema sem irrigação. Além disso, a adoção do sistema irrigado exige maiores gastos com fatores domésticos, a exemplo da aquisição de equipamentos e energia.

Em ambos os sistemas avaliados, verificou-se que os preços privados excederam suas valorações sociais, fazendo que o produtor pagasse $11,7 \%$ e $4,7 \%$ a mais, respectivamente, para áreas motomecanizáveis com irrigação e áreas não motomecanizáveis sem irrigação, por kg de palmito de pupunha produzido.

Ademais, é relevante ressaltar que a parcela majoritária do custo total do palmito pupunha se concentra nos insumos comercializáveis, nos dois sistemas produtivos analisados (Tabela 2). Essas informações indicam que os gastos com insumos comercializáveis são responsáveis por 73,69\% e 77,21\%, respectivamente, do custo total dos sistemas de produção do palmito de pupunha, em áreas motomecanizáveis com irrigação e em áreas não motomecanizáveis sem irrigação.

Outro aspecto a ser discutido refere-se às transferências financeiras associadas à lucratividade. Para Ferreira Neto (2005) e Moss (2006), essas transferências representam o principal resultado da MAP, pois esse valor indica a extensão da ineficiência de um sistema agrícola de produção, tendo em vista que se refere à soma de todas as divergências que fazem que os lucros privados sejam distintos dos benefícios sociais.

Revista Árvore, Viçosa-MG, v.35, n.6, p.1287-1297, 2011 
As informações da Tabela 2 apontam, também, transferências líquidas negativas, nos dois sistemas, da ordem de $\mathrm{R} \$ 3,20$ e $\mathrm{R} \$ 3,82$ por $\mathrm{kg}$, respectivamente, nos sistemas (I) e (II). Nesse sentido, apesar de tais sistemas operarem com lucratividade, os produtores de palmito de pupunha obtiveram menores lucros, que podem ser resultantes de taxações impostas à produção e à comercialização. Em outras palavras, tais produtores poderiam ter alcançado maior lucratividade, não fossem essas políticas distorcivas.

Quanto aos indicadores privados e sociais, constatou-se que a razão do custo privado (RCP) registrou valores positivos e inferiores à unidade, em ambos os sistemas considerados. Isso significa que a taxa de retorno dos fatores domésticos excedeu seu retorno normal, o que representa, portanto, uma atividade lucrativa sob a ótica econômica.

Com base no indicador do custo dos recursos domésticos (CRD), pode-se inferir que ambos os sistemas de produção enfocados são eficientes na produção de palmito de pupunha e propiciam ganhos líquidos para o Brasil. Esse indicador apresentou valores menores que 1. Dessa forma, apenas R \$0,33 e R \$0,28 foram gastos com recursos domésticos na geração de $\mathrm{R} \$ 1,00$ de divisas através de exportação, nos sistemas (I) e (II), respectivamente.

Feitas essas considerações, verificou-se que entre os dois sistemas produtivos analisados o sistema praticado em áreas não motomecanizáveis sem irrigação apresentou maior eficiência econômica na alocação de recursos. A expansão desse sistema de produção gerou ganhos líquidos de $\mathrm{R} \$ 0,72$, enquanto o regime adotado em áreas motomecanizáveis com irrigação propiciou ganhos líquidos de $\mathrm{R} \$ 0,67$.

Quanto aos coeficientes de proteção nominal sobre produtos comercializáveis (CPNp), os dados contidos na Tabela 3 mostram que ambos os sistemas de produção tiveram valores de 0,76 . Isso indica que a atividade está desprovida de proteção, pois o preço interno recebido pelo produtor é inferior ao preço vigente no mercado internacional. Essa diferença entre os preços sociais e privados é repassada, ou seja, a parcela que os produtores deixam de receber (24\%) é transferida para os consumidores. Isso é decorrente de taxações implícitas sobre esses sistemas produtivos.
Com relação aos coeficientes de proteção nominal sobre insumos comercializáveis (CPNi), é válido destacar a presença de transferências negativas dos produtores para a sociedade, independentemente do sistema produtivo. Tais transferências são de $12 \%$ e $31 \%$ nos sistemas (I) e (II), respectivamente. Portanto, os produtores de palmito de pupunha que adotam o sistema produtivo em áreas não motomecanizáveis sem irrigação receberam taxação maior em comparação com o outro sistema.

A taxação no setor produtivo do palmito de pupunha também é confirmada por meio do coeficiente de proteção efetiva (CPE), que apresentou valores inferiores à unidade, tanto no sistema (I) quanto no (II), de 0,44 e 0,35 , respectivamente, mostrando que as políticas públicas distorcivas foram danosas à atividade analisada.

Segundo Alvim et al. (2004), esse coeficiente estima quanto as políticas que interferem no mercado de produtos fazem que o valor adicionado se diferencie do valor que vigoraria na ausência de efeitos de políticas governamentais, identificando a extensão dos incentivos recebidos das políticas governamentais pelos sistemas produtivos.

Ferreira Neto (2005) e Moss (2006) ressaltaram, entretanto, que tal coeficiente apresenta limitação como indicador de incentivos, tendo em vista que não incorpora os efeitos de políticas que influenciam os preços dos fatores domésticos, mas apenas políticas que interferem nos preços dos fatores comercializáveis. Portanto, o CPE deveria ser considerado como indicador parcial dos efeitos de incentivos das políticas sobre os preços do produto e dos insumos comercializáveis e não como indicador total que capta o efeito total de políticas que influenciam todos os preços e custos. Para superar essa deficiência, adota-se o coeficiente de lucratividade (CL) como indicador completo, que mede o efeito global das transferências líquidas provenientes de políticas intervencionistas.

Neste estudo, os coeficientes de lucratividade apresentaram valores inferiores à unidade e próximos de zero nos sistemas de produção (I) e (II), indicando total falta de proteção. Essa atividade foi liquidamente taxada, com redução do lucro privado, gerando transferência dos produtores para a sociedade.

A existência de taxação e desproteção na produção do palmito de pupunha também é corroborada pela taxa de subsídios aos produtores (TSP), visto que esse 
indicador ocasionou redução de $31 \%$ e $38 \%$, respectivamente, na rentabilidade dos sistemas produtivos (I) e (II).

\section{CONCLUSÕES}

Os resultados indicaram que a produção de palmito de pupunha no Brasil é competitiva nos dois sistemas avaliados, tendo em vista que apresenta lucratividade positiva em ambos os sistemas, tanto do ponto de vista privado quanto social.

A rentabilidade, entretanto, poderia ter sido maior e, consequentemente, também a competitividade, se não fossem as políticas governamentais que afetam a atividade, ocasionando divergências entre os preços do palmito de pupunha nos mercados interno e externo, assim como entre os custos dos insumos comercializáveis privados e internacionais. Essas políticas, resultantes de taxações impostas à produção e à comercialização do palmito de pupunha, são danosas aos produtores.

Nesse sentido, políticas públicas destinadas à desoneração tributária incidente sobre a produção e comercialização do palmito de pupunha no Brasil deveriam ser implementadas para fortalecimento da atividade, no intuito de gerar maior lucratividade e competitividade.

Ademais, sugere-se que em estudos posteriores seja realizada análise comparativa da competitividade do palmito, mediante o emprego da MAP, considerando diferentes regiões produtoras, assim como horizontes temporais distintos, com vistas à contribuição para o desenvolvimento dessa atividade.

\section{REFERÊNCIAS}

AHMAD, S.; MARTINI, R. P. Agricultural Policy Analysis in Pakistan: Illustrations in the use of the Policy Analysis Matrix. Working Paper, 2000.

\section{Alves, J. M. Competitividade e tendência da produção de manga para exportação do nordeste do Brasil. 2002. 163f. Tese (Doutorado em Ciências: Área de Concentração - Economia Aplicada) - Escola Superior de Agricultura “Luiz de Queiroz”, Universidade de São Paulo, Piracicaba, 2002.}

ALVIM, M. I. et al. Análise da competitividade da produção de soja nos sistemas de plantio direto e plantio convencional na região do Cerrado Brasileiro. Revista de Economia e Sociologia Rural, v.42, n.2, p.223-242, 2004.
BANCO NACIONAL DE DESENVOLVIMENTO ECONÔMICO E SOCIAL - BNDES. Departamento de Estratégias do Desenvolvimento.

Competitividade: conceituação e fatores determinantes. Rio de Janeiro: 1991. 26p.

BENTES-GAMA, M. M.; SCOLFORO, J. R. S.; GAMA, J. R. V. Potencial produtivo de madeira e palmito de uma floresta secundária de Várzea Baixa no Estuário Amazônico. Revista Árvore, v.26, n.3, p.311-319, 2002.

BOVI, M. L. A. O agronegócio palmito de pupunha. O Agronômico, v.52, n.1, p. 10-12, 2000.

\section{CENTRO DE DESENVOLVIMENTO DO}

AGRONEGÓCIO - CEDAGRO. 2007.

Coeficientes técnicos. Disponível em:

$<$ http://www.cedagro.org.br $>$ Acesso em: 14 de jun. de 2008.

CHAIMSOHN, F. P. Producción y calidad del palmito al natural, em función de la población, del arreglo de plantas y del tipo de fertilización. 2006. 205f. Tese (Doutorado em Sistema de Produção Agrícola Tropical Sustentável) - Universidad de Costa Rica, Costa Rica, 2006.

CHAIMSOHN, F. P. Cultivo de pupunha e produção de palmito. Viçosa, MG: Aprenda Fácil, 2000.121p.

ENDOM, M. A. Economic analysis of large scale logging. Working Paper, $\mathrm{n}^{\circ}$. 3, 1999.

Disponível em: <http://www.worldagroforestry.org/ sea/Publications/files/workingpaper/WP002104.PDF>. Acesso em: 07 de jul. de 2008.

FANG, C.; BEGHIN, J. C. Food self-sufficiency, comparative advantage, and agricultural trade: a policy analysis matrix for Chinese agriculture. October. 2000 (Revised). Working Paper 99WP 223. Disponível em: <http:// www.card.iastate.edu/publications/texts/ 99wp223.pdf> . Acesso em: 19 de dez. de 2008.

FERREIRA NETO, J. Competitividade da produção de cana-de-açúcar no Brasil. 2005. 87f. Dissertação (Mestrado em Economia Aplicada) - Universidade Federal de Viçosa, Viçosa, MG, 2005.

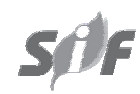

Revista Árvore, Viçosa-MG, v.35, n.6, p.1287-1297, 2011 
HADI, P. U.; BUDHI, G. S. Analysis of the economic efficiency and comparative advantage of the sumatran smallholder rubber using "PAM" Method. Working Paper, $\mathrm{n}^{\circ}$. 4, 1997. Disponível em: $<$ http://www.wrldagroforestrycenter.org/sea/ Publications/files/workingpaper/WP0022-04.PDF>. Acesso em 22 de ago. 2008.

HAGUENAUER, L. Competitividade: conceitos e medidas: uma resenha bibliográfica recente com ênfase no caso brasileiro. Rio de Janeiro: Universidade Federal do Rio de Janeiro - Instituto de Economia Industrial, 1989. 20p. (Texto para Discussão, 211)

HERNANDEZ, F. B. T. Irrigação na cultura da pupunheira no noroeste paulista. Disponível em: http://www.agr.feis.unesp.br/ aracatuba.htm. Acesso em 19 de dez. 2008.

IE/UNICAMP - IEI/UFRJ - FDC - FUNCEX. Estudo da competitividade da indústria brasileira. Sistema de indicadores da competitividade. Campinas: 1993. 202p. (Nota Técnica)

INSTITUTO DE ECONOMIAAGRÍCOLA - IEA. Estatísticas. (2009). Disponível em: http:// www.iea.sp.gov.br. Acesso em: 05 de jan. 2009.

\section{INSTITUTO DE PESQUISA EM ECONOMIA} APLICADA - IPEA. Disponível em: http:// www.ipeadata.gov.br. Acesso em: 20 de fev. 2009.

MARRA, R. et al. Cadeia produtiva do café em Minas Gerais. In.: VIEIRA, R. C. M. T. et al. Cadeias produtivas no Brasil: análise da competitividade. Brasília: Embrapa Comunicação para Transferência Tecnológica/Secretaria de Administração Estratégica, 2001. p.139-154.

MARTINS, P. C. Efeitos de políticas públicas sobre a cadeia produtiva do leite em pó. In: VIEIRA, R. C. M. T. et al. Cadeias produtivas no Brasil: análise da competitividade. Brasília: Embrapa Comunicação para transferência tecnológica/Secretaria de Administração Estratégica, 2001. p.241-272.

MARYANI, R.; IRAWANTI, S. Economics analysis of land use system for Large scale plantations of oil palm and industrial timber estate. Working Paper, $\mathrm{n}^{\circ} .2$, 1997. Disponível em: http://www.worldagroforestry.org/ Sea/Publications/files/workingpaper/WP002004.pdf >. Acesso em: 07 de jul. 2008.
MERECÍ, K. Palmito. 2008. Disponível em: http//:www.mailxmail.com. Acesso em: 3 de fev. 2009.

MOHANTY, S.; FANG, C.; CHAUDHARY, J. Assessing the Competitiveness of Indian Cotton Production: A Policy Analysis Matrix Approach. Working Paper, 2002. Disponível em:< http:// www.card.iastate.edu/publications/DBS/PDFFiles/ 02wp301.pdf > . Acesso em: 08 de jul. /07/2008.

MONKE, A. E.; PEARSON, S. R. The policy analysis matrix for agricultural development. New York: Cornell University Press, 1989. 278p.

MOSS, S. R. Competitividade da produção do café arábica em Minas Gerais e São Paulo. 2006. 90f. Dissertação (Mestrado em Economia Aplicada) - Universidade Federal de Viçosa, Viçosa, MG, 2006.

NELSON, A. W. Applications of the Policy Analysis Matrix (PAM). Working Paper, 1991. Disponível em:< http://www.ifpri.org/training/ material/miscellaneous/Foodpolicycom/ AppendixF_policymemoranda.pdf $>$. Acesso em: 08 de jun. 2008.

NELSON, C. G.; PANGGABEAN, M. "The Costs of Indonesian Sugar Policy: A Policy Analysis Matrix Approach." American Journal of

Agricultural Economics, v.73, p.703-712, 1991.

PADILHA, N. C. C.; OLIVEIRA, M. S. P.; MOTA, M. G. C. Estimativa da repetibilidade em caracteres morfológicos e de produção de palmito em pupunheira (Bactris gasipaes Kunth). Revista Árvore, v.27, n.4, p.435-442, 2003.

ROSADO, P. L. Competitividade e expansão da avicultura e suinocultura no contexto do MERCOSUL. 1997. $105 f$. Dissertação (Mestrado em Economia Rural) Universidade Federal de Viçosa, Viçosa, MG, 1997.

ROSADO, P. L.; TOSTO, S. G.; GOMES, M. F. M. Competitividade e expansão da produção de borracha natural brasileira, no contexto de liberalização dos mercados. In: ALVARENGA, A. P. et al. Seringueira: Aspectos econômicos sociais e perspectivas para o seu fortalecimento. Viçosa, MG:Universidade Federal de Viçosa, 2006. p.103-128. 
SAMPAIO, L. C. et al. Análise técnica e econômica da produção de palmito de pupunha (Bactris gasipaes Kunth.) e de palmeira-real (Archontophoenix alexandrae Wendl. \& Drude). Revista Floresta e Ambiente, v. 14, n. 1, 14-24, 2007.

SERVICIO DE INFORMACIÓN Y CENSO AGROPECUARIO -SICA (2009). Ecuador: Precio de los Principales Insumos Agrícolas. Disponível em: http:// www.sica.gov.ec/agro/insumos/ Boletin insumos.htm. Acesso em: 12 de fev. 2009.
VERRUMA-BERNARDI, M. R. et al. Análise descritiva quantitativa do palmito de pupunheira. Acta Amazonica, v.37, n.4, 507-512, 2007.

VIEIRA, R. C. M. T. et al. Cadeias produtivas no Brasil - análise da competitividade. Revista de Política Agrícola, v.10, n.4, p.7-15, 2001.

VILLACHICA, H. Cultivo del pijuayo (Bactris gasipaes Kunth.) para palmito en la Amazonia. Lima, Peru: FAO/Tratado de Cooperacion Amazonica, 1996. 153p. 
